\title{
Digital transformation and the renewal of social theory: unpacking the new fraudulent myths and misplaced metaphors
}

\author{
Marinus Ossewaarde, University of Twente, Department of Public Administration. \\ m.r.r.ossewaarde@utwente.nl
}

\begin{abstract}
In this article, it is argued that social theory must be renewed to comprehend the new power constellations and new challenges to aesthetic and intellectual ways of life that are being shaped by digital transformation. However, while social theory has to renew its tools in order to grasp previously unknown realities, it also runs the risk of being assimilated into the very process that it seeks to understand, or to assimilate so much of the dominant belief system that it loses its critical and creative potential. The aim of this article is to propose a particular, renewed social theory that consists in a recasting some social theoretic insights to be able to preserve aesthetic and intellectual potentials of critique and negation. Through the lens of this renewed social theory, digital transformation is understood as a form of economic domination, which, as this article shows, is sustained by un-enlightenment, that is, by fraudulent myths and misplaced metaphors.
\end{abstract}

\section{Keywords}

Digital transformation, metaphor, myth, Silicon Valley, social theory

\section{Introduction}

Digital transformation is generally theorized as a process by which social existence is increasingly affected by digital processes, digital tools, and abundance of information (Lundgren, 2017). As a result, a new hybrid world arises, in which experience is constituted by the merging of the physical world with the digital world. In the digital age, digital processes are so deeply embedded in the daily life of information capitalism that people barely realize they interact with devices and operate machines (Van de Boomen, 
2014; Lupton, 2015; Turkle, 2015; Hess and Davisson, 2018). It is evident that hermeneutic social theory needs to take digital transformation into account (Schroeder, 2018; Ossewaarde, 2018). A renewed hermeneutic social theory is necessary to understand the new age initiated by digital technologies and algorithmic modernization. "Classical" social theory arose in a context of industrialization, where the pervasive effects of automatization were known but those of digitalization were as yet unknown. Given the transformation of the industrial context, hermeneutic social theory has to renew its tools in order to grasp previously unknown realities (cf. Fuchs, 2017a). However, in this process of renewing, hermeneutic social theory runs the risk of being assimilated into the very process that it seeks to understand, or to assimilate so much of the digital age's dominant language and belief system that it loses its poetic sensibility and its critical, interpretative, and creative potential.

In order to understand the "digital transformation of social theory", it is argued in this article, that digital transformation is, to a high extent, a Silicon Valley-driven process that impacts on hermeneutic social theory's intellectual potentials. It must be emphasized that the type of social theory that is discussed, and renewed, in this article is a particular social theory that has emerged from the Weberian and hermeneutic traditions. In what follows, the argument of this paper is constructed in seven steps. First, Max Weber's theory of value spheres is introduced, as an "old" social theory that makes us sensitive to the problematic relationship between the economic sphere, on the one hand, and the aesthetic and intellectual spheres, on the other hand that is typical for a technological age. Second, while industrial and digital technologies emerge from the economic sphere, hermeneutic social theory emerges from the aesthetic and intellectual spheres. Third, in the industrial age, the economic sphere comes to usurp other spheres, particularly through the spreading of industrial technologies. While economization may have different meanings according to different social theoretic orientations, in this article it is argued that economization assumes the form of economic domination or capturing of other spheres. While the economic sphere as such is most valuable and necessary for the very existence of other spheres, the economization that emerges in the technological age is interpreted, in this article, as a form of usurpation, comparable to, for instance, the religionization and politicization of former ages. Such domination affects the critical, reflective, and expressive capacities on which hermeneutic social theory relies. Fourth, in the industrial age, hermeneutic social theory developed in defense of the aesthetic and intellectual spheres, against economization of beliefs and language. Hence, hermeneutic social theory, while it may certainly embrace technologies and capitalism, typically tends to assume the form of a technology critique, in an intellectually problematic context of usurpation. Social theory in general does not necessarily reject technology and information capitalism: in fact, technology, including Windows, Apple and Google tools, 
may well be used to generate new social theoretic insights (cf. Roth et al, 2017; Roth et al, 2018). Fifth, in the digital age, economization as understood in this article comes to assume the form of digital transformation, in the sense that digital transformation, which may be a most welcoming process, tends to be hijacked by dominating powers. Sixth, in both the industrial and digital age, fraudulent myths emerge from dominating powers that emerge from the economic sphere (while in previous epochs such myths typically emerged from the political and religious spheres). . A renewed social theory needs to be created to be able to show the fraudulent myths of the digital age. And finally, it is argued that the fraudulent myths of the industrial and digital age are sustained by language itself, through misplaced metaphors. In the digital age, a variety of misplaced metaphors are generated. Such metaphors express misconceptions of the intellectually problematic realities of the digital age. It is the task of a renewed hermeunitic social theory to criticize and negate them.

\section{Social theory and the aesthetic and intellectual spheres}

The type of social theory that is discussed in this paper can be understood as a defense of the poetic and sociological imagination, in a struggle against religious, political and economic forces of domination that close the mind. It is through the poetic and sociological imagination that this particular social theory is able to expose, criticize and negate the falsehoods, prejudices and knowledge aversion that are reinforced through domination. Digital transformation can be understood as an economic force of domination that is mainly associated with the oligarchic power constellation of Silicon Valley. Economic processes are involved in how digital technologies operate (Noble, 2018). Siva Vaidhyanathan (2012) metaphorically dubs this economic domination as "the googlization of everything", with Google having emerged as the chief architect of digital transformation. In the digital age, digital or algorithmic technologies and its associated powers (tech firms like Google) become omnipresent. An important task for such a social theory is to critically articulate the process of digital transformation as a new form of economic domination. Social theory thereby protects itself from becoming the instrument of economic domination or "the googlization of everything", in defense of the poetic and sociological imagination.

More than any other of the old social theorists, Weber asserts that social theory serves no other purpose than protecting the aesthetic and intellectual qualities of mind. The idea of a clash between a dominating economic sphere on the one hand and social theory on the other hand can be found in Weber's theory of value spheres (Weber, 1958, pp. 323-359; Lash, 1990, p. 157). In this theory six spheres are distinguished: the religious, economic, political, erotic, aesthetic, and intellectual spheres. These 
spheres clash: each value sphere develops from within, on the basis of its own values, institutional framework or traditions, actors at play, and type of committed action (Oakes, 2003). Originally, the religious sphere dominates all spheres. The religious sphere, which is the original sphere from which all other spheres develop, is marked by other-worldliness (and hence the contradiction between religion and the world), an ethic of brotherliness, a community bond of faith, regulated sexuality, and the quest for redemption, holiness and salvation. In the modern age, which emerges from the creedal wars of the West European Reformation, the political sphere comes to dominate other spheres. In the modern age, the political sphere is represented by the sovereign state, defined by its regulation of violence and administration of justice. In the industrial and the digital age, the economic sphere comes to dominate the other spheres. The economic sphere, emancipated from religion and politics, is represented by the market, characterized by competition, money prices, calculation, contractual relations, technological innovations, and a businesslike attitude.

Confronted with religionization, politicization and economization, its existence is precarious. Both the aesthetic and intellectual spheres typically find their life orders becoming invested with non-aesthetic and non-intellectual values, frameworks, actors and commitments; and sucked into the religious, political and economic routines of everyday life. The aesthetic sphere is defined by the quest for overcoming such routines (Weber, 1958, p. 341; p. 342). This is achieved through the poetic imagination, from which myths and metaphors emerge. In the aesthetic sphere, worlds are created out of words that are not part of everyday religious, political and economic routines. Social theorists need the great poets and novelists to develop their sense of awe, sensitivity, eye for detail and contradiction, and deeper insights. Given this need for poetic creativity, playfulness and refinement, social theory is committed to the guardianship of the poetic imagination and literary language of the aesthetic sphere, against the invasion of everyday language that emerges from the religious, political and economic spheres (Jacobsen and Marshman, 2008; Meloni, 2014; Collin and Pedersen, 2015; Ossewaarde, 2018).

The intellectual sphere is defined by the quest for academic knowledge and "a reasoned view of the world" (Weber, 1958, p. 355) that involves an inner devotion to the scientific tasks of theorizing, reflection, erudition, demonstration, clarification, understanding, etc. Sociological imagination is needed for constructing such "a reasoned view of the world" - a world that is contrasted with an unreasoned (false, fraudulent, biased, prejudiced) view of the world that is reinforced through the religious, political or economic domination of the intellectual sphere. The sociological imagination is meaningless if it is not both poetic and sociological: resisting the unreasoned view requires the capacity to shift perspectives and hence a certain playfulness towards the phrases and words (Mills, 2000, pp. 211-212). Weber himself 
tragically foresaw the domination of the intellectual sphere and the downfall of the Bildungsuniversität as the center of the culture of mind to which he was committed. Industrial processes had started reshaping the intellectual sphere in an economic image, so that it may no longer be possible to uphold the academic standards of thought, taste and feeling that make social theory possible. In the industrial age, "scientific work," Weber (1958, p. p. 137) observes, "is chained to the course of progress". In the subservience to the techno-economic rule, academic endeavors come to gain legitimacy when they adopt the everyday economic language and imagination of the dominating sphere (Schroeder and Swedberg, 2002). For Weber, the authentic social theorist is an intellectual hero who is inwardly or passionately devoted to intellectual integrity, in resistance to religious, political or economic forces that compromise that integrity.

\section{Social theory, digital transformation and the economic sphere}

With digital transformation being the buzzword for "the course of progress" in the digital age, it is argued in this paper that the renewed particular social theory is not to be chained to digital transformation and its techno-economic dictates. The hegemony of the economic sphere leads to the marginalization of the poetic imagination and literary language in (hermeneutic) social theory, which affects its poetic sensibility and capacity for imagining social alternatives. Correspondingly, the poetic creativity and sensitivity of the hermeunitic social theorist as presented in this article are underused or unused, and with time, get lost. More than Weber, Horkheimer and Adorno have recourse to the poet's toolbox (aesthetic style, myth and metaphor) in order to uncover the compromising of the intellectual sphere: in the industrial age, science and technology have degenerated from being creative forces of liberation and enlightenment into creativity-restricting industrial structures of Fordist standardization, mechanization and mass production (Collin and Pedersen, 2015). Economization, Horkheimer and Adorno (2002, p. 28) explain, means that the "mind becomes in reality the instrument of power," instead of being critical of power. For Horkheimer and Adorno, the "culture industry" is the most dramatic techno-economic domination of the intellectual and aesthetic sphere. The culture industry economizes leisure, discussions, opinions and information, transforming intellectual phenomena into economized entertainment for a passive audience of mass consumers. With the rise of the culture industry in the industrial age of ubiquitous television, the power of art and science to affect minds is weakened. 
Not all social theorists are so hostile to the world of the industrial or digital age. Various social theorists seek to find a home for a renewed social theory within a societal context that is subject to technological transformation. Their necessary renewal of social theory can be understood as an adjustment of social theory to the linguistic requirements of a new technological age. Niklas Luhmann (1982), for instance, renews social theory into systems theory described in the cybernetic language of "autopoiesis", "self-referentiality", "stability”, "disturbance”, "system”, "environment", "regulation" and "feedback", so as to make sense of constancy and invariance in transforming worlds. James Coleman (1990) replaces the literary language of social theory by a so-called technical rigor, by rewriting a corpus of social theory into mathematical formula. Coleman seems to accept the hegemony of the industrial logic of mechanization and integrates it into his own social theory. In a somewhat similar vein, W.G. Runciman (2008) argues that with the rise of the bio-technologies and neuro-technologies, the social theorist may be well advised to adopt the biological language. Runciman advocates adopting Darwinian metaphors and reinventing a new vocabulary for social theory, made of hybrid naturalist notions such as "social selection" and "cultural selection" (cf. Meloni, 2014). Such reworked definitions of other types of social theory necessarily imply departures from the hermeneutic type of social theory that is discussed in this article.

Luhmann (1982), for instance, makes the concept of functional differentiation the core of his renewed social theory. Functional differentiation is an alternative concept for the domination lens. Functional differentiation refers to a distinction of interdependent yet contradicting function systems (including polity, economy, science, art, religion, legal system, sport, health, education and media) that, for Luhmann, is the main attribute (of complexity, dynamics and openness) of the industrial and digital age (Roth et al, 2017; Roth et al, 2018). In contrast with value spheres, function systems are defined by (environmental, that is, multi-system) complexity reduction and operational closure, with no function system (including religion, polity and economy) every being powerful enough to be able to control interdependencies between function systems in their environment (Valentinov et al, 2018). Economization, for Luhmann, accordingly, does not mean economic domination, but refers to the extent the economic system is able to control other function systems. Given Luhmann's systems theory, economization, like religionization and politicization, can only be highly limited: no function system can control other systems. Roth et al $(2017 ; 2018)$ observe that economization does not take place. The economy never had a dominant position in capitalist society. A social theoretic focus on economization is but a manifestation of neglect of other function systems, which follows from a social theorist's "observational bias to the economy at the cost of a lack of observation of science, art, religion, law, health, education, sport and the mass media system" (Roth, 2015, p. 119). 
Weber's old social theory and Luhmann's systems theory offer two very different theoretical orientations that offer different routes for renewing social theory in the digital age. Luhmann's systems theory can be used, for instance, to reveal the fundamental uncontrollability of a differentiated technological society (Valentinov et al, 2018); or to draw attention to the diversity of function systems (and to de-focus on the economic system) in a digitally transformed world (Roth, 2015; Roth, 2017). Weber's theory of spheres, by contrast, reflexively grounds social theory in the aesthetic and intellectual spheres. In a renewed form, it can be used for revealing new struggles of cultural (aesthetic and intellectual) forces against new domination in the digital age. Again, the social theoretic critique of digital transformation is not necessarily anti-technological or anti-economic: it is against the attack on the culture of the mind. Given the description of the hermeneutic type of social theory as discussed in this article, such an attack on the mind is, among other things, found in scientific adoptions of the industrial or digital language, which is then identified as a weakening of the negation potential of social theoretic language (Clegg, 2015). Without the negation potential, industrial and digital jargon is uncritically endorsed; and the myths and metaphors of tech oligarchs are allowed to permeate science itself, so that the boundary between truth and falsehood becomes blurred.

Even more than in the industrial age, the digital age calls for a particular renewed social theory that uncovers the particular falsehoods that come with the digitalization or "googlization" of the intellectual sphere. The digital era is marked by the so-called "knowledge economy" and ubiquitous computing. Algorithmic processes emerging from the economic sphere reshape the intellectual sphere in accordance with the dreams of Silicon Valley (Berry, 2014). The nature of digital technology makes it easy to infiltrate all spheres, including the university (Williamson, 2017), without being perceived as an intruder. On the contrary, similarly to industrial technology that used to be marketed as relieving the burdens of labor, digital transformation is presented as generating more knowledge or more enlightenment. These two elements - its omnipresence and its good image - result in the readier adoption of the simple, digital language. This happens nearly unconsciously, through the everyday exposure to the digital jargon. Its influence can be seen in the intellectual sphere. Given the fact that a language is not simply a tool to transmit information, but is instead the fruit of ideas, beliefs, values, feelings, and experiences of the world, the greater the influence of the digital language that emerges from the economic sphere, the greater the loss of the rich poetic language of social theory that emerges from the aesthetic sphere. The richer a language, the richer the experience and understanding of the world. The converse also holds. Hence the strong dependence of the Weberian type of social theory on the aesthetic sphere. 


\section{The fraudulent myth of digital transformation}

Horkheimer and Adorno theorize a dialectic of enlightenment for the industrial era - an epoch that is marked by the technological development of mass production, automatization, new communication means (mainly radio and television), the culture industry, and industrial tools endowed with an apocalyptic power of devastation. A similar dialectical process can be theorized for the digital era (cf. Could, 2014). The core of Horkheimer and Adorno's old social theory is that myth (which emerges from the aesthetic sphere) and science (which emerges from the intellectual sphere) are not opposites but complementary (Cohen, 2010). With the progress of science and technology, old myths do not vanish but, transmitted by the pre-industrial worlds' poetry, continue to excite, propel, impregnate and stimulate the poetic imagination. Homeric myths, Horkheimer and Adorno stress, do not belong to an epoch, but are underlying constants in European culture. Horkheimer and Adorno reject both the enlightenment claim that scientific thought consists in myth criticism (which intellectualizes the aesthetic sphere) and its opposite, the romanticist guardianship of myth (which aestheticizes the intellectual sphere). In their own work, they use myths - mainly Homeric myths, like the Odyssey legend and the Song of the Sirens - to draw the parallel between the deafened sailors in Homer's Odyssey and the fate of many living through everyday life of the industrial age (Horkheimer and Adorno, 2002, p. 27). They use Homeric myths to reveal the anti-intellectual structures of economization, the reinforcement of falsehood in the industrial age.

Horkheimer and Adorno (2002, p. 9) distinguish between "genuine myth" and "fake myth". A genuine myth is part of an aesthetic tradition (like the Homeric tradition) and leads to enlightenment, in the sense that it opens up new perspectives and therefore provides deeper insights into the realities of existence. In the Odyssey myth, for instance, various insights are communicated to the Greeks, including Odysseus' duties of carrying out acts of justice and rejecting Calypso's offer of immortality. A fake myth, by contrast, does not open any new window onto new realities, but instead is manufactured to legitimize anti-intellectual structures and the existing views and states of affairs. Such a myth, packed in deceptive clichés, stereotypes, slogans, prejudices and ready-made images, obscures realities of domination and prevents their criticism. A fake myth or "fraudulent myth" divorces myth and enlightenment, to the point that people are blinded or deafened, just like Odysseus' sailors who had been ordered to put beeswax in their ears ("with their senses forcibly stopped" (Horkheimer and Adorno, 2002, p. 27)), so that they would 
become immune to the lethal beauty of the Sirens. Fascism and anti-Semitism are, for Horkheimer and Adorno, the clearest examples of fake myths. Manufactured myths of the Führer and the master race provide false projections and channel aggressiveness and hostilities by venting rage "on those who are both conspicuous and unprotected" (Horkheimer and Adorno, 2002, p. 140).

The Homeric myth of the Sirens can be applied to Silicon Valley. The Song of the Sirens can be conceived as a metaphor for all sorts of seductions - not only erotic or aesthetic ones (the irresistible beauty of the Sirens chanting a marvelous song), but also technological seductions. Silicon Valley's technological marvels indeed hold people under their spell (Van der Laan, 2004; Couldry, 2014). Silicon Valley fabricates its own fake myths to obscure the anti-intellectual structures of the digital age and to legitimize the status quo of the digital age - a status quo in which Silicon Valley itself is a ruling oligarchical power that holds a monopoly on public information about individuals and groups (Noble, 2018). The tech oligarchs are worshipped as the revolutionary heroes of the digital age. Judy Wajcman (2017) points out that "digital transformation" is itself such a fraudulent myth. The narrative in which digital technology, including big data, is a game changer, a uniquely disruptive force, and the manly and white tech entrepreneurs are the new heroic revolutionaries is a fake myth that obscures reality (cf. Couldry, 2014). The myth of the digital transformation hides the anti-intellectual algorithmic structures that are designed and fabricated in accord with their particular interests, biases, prejudices, superstitions, and "alternative facts" (Noble, 2018). Ed Finn (2017) explains that in the digital transformation myth, algorithms are presented as a pinnacle of Enlightenment. Such a myth obscures that digital technologies are driven by computational efficiency and, given such drive, transform the quest for knowledge into a "spectacle that occludes the real decisions and trade-offs behind the mythos of omniscient code" (Finn, 2017, p. 8) A typical episode of the digital transformation myth, Wajcman points out, is the story that "the robots are coming", to take over economic activities. That is a manufactured myth that vents rage on those whose jobs may be lost (cf. Jordan, 2015; Finn, 2017; Aschoff, 2018). In revealing the myth of the digital transformation, Wajcman (2017, p. 126) emphasizes that "the homogeneity of the Silicon Valley creators is a more dangerous threat to the future than any perceived robotic apocalypse."

The "Silicon Valley creators" not only design and produce digital technologies, but they also create the myth of digital transformation (cf. Andriole, 2017). The fraudulent myth of digital transformation that "Silicon Valley creators" manufacture is the futuristic story or "techno-tale" that, when ubiquitous computing is managed well (and only the Silicon Valley oligarchs can manage that process well, the story goes), algorithmic technologies will change the world for the better and even enhance a culture of enlightenment. Silicon Valley's futuristic story of digital transformation contains the promise that the 
envisioned or "divined" technological breakthroughs of the future will lift people out of the antiintellectual structures of everyday life and provide access to another, less knowledge averse reality (Dourish and Bell, 2011). The Silicon Valley techno-tale of digital transformation not only hides the intellectual and aesthetic homogeneity of Silicon Valley, but also hides the fact that the envisioned digital transformation of the future signifies further, and more penetrating, economic domination by Silicon Valley forces. The realization of the futuristic vision of digital transformation requires the imposition of Silicon Valley's business modes of investigations, its forms of communication - or rather non-conversation - , its ways of asking questions (to which it already has the answers), its plans, its designs, its interventiontechniques, its tools, etc. that come with its economic domination (Philip, Irani and Dourish, 2012; Fuchs, 2017b). Silicon Valley is dominated by economic concerns, including entertainment, efficiency and comfort: it is not known for its intellectual and aesthetic richness even though it would like to create that illusion (Schroeder and Ling, 2014).

In other words, it is not digital technology, but instead fraudulent myth that constitutes the main "cause" of digital transformation. The Silicon Valley myth of digital transformation hides the oligarchical power structure of the digital age. As a fake myth of technologically driven liberation and democratization, presented as revolutionary, it does not provide enlightenment, but instead obscures the status quo of oligarchical power relationships. The myth of digital transformation shapes the total institutional framework of the digital era, including technologies, policies, programs, procedures, etc. The myth enables oligarchical powers to get away with brutalization (for instance, in the form of corporate scandals (data scandals), like the Facebook scandal, Cambridge Analytica scandal, the Google walk-out scandal, etc. (cf. Jordan, 2015)), while aesthetic and intellectual energies, creativity and imagination are taken up with economic activity. Digital technologies owe their existence to, and sustain, the myth of digital transformation. They therefore inevitably obscure contradictions and alternative realities beyond corporate oligarchy. It is the task of the particular renewed hermeneutic social theory to enlighten such obscurity, in defense of a culture of enlightenment in the digital age.

\section{The misplaced metaphors of digital transformation}

Myths - both genuine and fake myths - are sustained through metaphors (Christensen and Cornelissen, 2015). Metaphors are figures of speech that describe phenomena in ways that are not literally true, but help explain an idea or make a comparison, by relying on known experiences (images) to make sense of 
new experiences. All thought, including the thought processes of the intellectual sphere (and hence social theory), is metaphorically mediated, through an act of metaphorical translation (Lakoff and Johnson, 1980; Nerlich and Clarke, 2001; Pigliucci and Boudry, 2011; Van de Boomen, 2014; Carbonell, SánchezEsguivillas and Carro, 2016). Social theory relies on appropriate metaphors: without such devices of the poetic imagination, there can be no theory. Conversely, hermeneutic social theory criticizes and negates misplaced metaphors. Such metaphors sustain prevailing false myths (Mumford, 2015). Given economization, misplaced metaphors infuse all value spheres. Such a social theory is not exempted from this danger, as noted at the outset. As Daniel Rigney (2001) emphasizes, fraudulent metaphors can be used to manipulate and present ideologically biased understandings of the world. "The hazards of metaphor in social theory are real enough", Rigney $(2001$, p. 5) warns.

In social theory in general, an appropriate metaphor enhances understanding. Weber, for instance, uses the metaphor of the "iron cage" (stahlharte Gehäuse) - which is borrowed from John Bunyan' The Pilgrim's Progress - to understand what it means to live in a technological world that is organized by mechanical forces and artificial mechanisms. Through the use of the metaphor of the iron cage - a prison -, Weber indicates that a technological world may be organized more efficiently but is not likely to become a free world. Freedom requires the creativity and imagination to transcend everyday structures and the fraudulent myths and misplaced metaphors that obscure such un-enlightenment. Such freedom is not found in the iron cage, which is a closed technological system without openings to new realities. Horkheimer and Adorno themselves create the metaphor of the "culture industry" to show how aesthetic expressions (music, literature, etc.) and the intellectual manifestations of the mind (ideas, conversations, consciousness, etc.) have become planned, formalized, technologized, standardized, and mass produced according to the factory logic. They thereby try to illustrate the lack of freedom to create and to think. The same taste, the same clichés, the same manners, and the same ideas are produced in the culture industry, which is a technology of mass deception. To capture the same unfreedom, Mills has recourse to his metaphor "the cheerful robot." The word "robot" was, of course, not created by him but by the writer Karel Čapek, in 1920, for whom robot meant "slave work." Like the slave, the cheerful robot has no autonomy of action, but is a governed object and a technologized being. Unlike the slave that longs for freedom, the cheerful robot is content to be a slave. A technological world affects the very desire to be free and to be humanized (aestheticized and intellectualized). "Cheerful robots" do not want to learn and create; they have no curiosity, do not converse (except with prefabricated opinions and clichés), and do not doubt or contest; and hence do not struggle for alternative realities. In this way, they become willing slaves, who sustain their own condition and, by their own slavish conduct, reproduce the anti- 
intellectual structures of the industrial age. "In our time, must we not face the possibility that the human mind as a social fact might be deteriorating in quality and cultural level, and yet not many would notice it because of the overwhelming accumulation of technological gadgets?," Mills (2000, p. 175) rhetorically wonders.

The use of technology metaphors - iron cage, culture industry, cheerful robot - by old social theorists manifests the profound impact of technological developments on social theory in the industrial age (cf. Pigliucci and Boudry, 2011). In the digital age, by contrast, non-technological metaphors may be more useful to understand digital phenomena. One such metaphor is Zygmunt Bauman's metaphor of liquidity. Through the use of this metaphor, Bauman captures, up to a point, the structural transformation of the industrial era, characterized by concrete machines and solid goods, into a digital age, characterized by fluidity and virtual goods (Jacobsen and Marshman, 2008). Bauman's metaphor of liquidity applied to digital transformation depicts the latter as a process that melts mechanized worlds, to the point that nothing in the digital age remains constant, secure, precise, fixed or stable; and nothing lasts for long. Algorithmic technologies, such as social media technologies, are quickly outdated, or rather, are made to be outdated. Through the use of his metaphor, Bauman asserts that newness, strangeness and ambivalence rather than computational logic define the digital age; yet, Bauman's metaphor fails to capture the continuation of economization in the digital age. Bauman's metaphor of liquidity describes digital transformation and makes sense of the social condition in the digital age but hides the fact that digital technologies rely on energies that are mostly produced in industrial ways. Tech firms, such as Apple, Amazon and Google, use lots of natural resources and electricity that are produced through industrial extractivism that relies on solid machinery. In other words, Bauman's metaphor of liquidity masks that digital liquidity here implies industrial solidity there. And the industrial solidity - or rather, the brutalization (tyrannical oppression and genocidal massacres in the Global South) that comes with industrial extractivism - is typically kept out of sight in the digital age or falsely disassociated from digital transformation.

Bauman's metaphor of liquidity is appropriate because it describes the new experience of the digital age, even though the metaphor is limited because it hides the industrial extractivism that is the solid foundation of digital technologies. Misplaced metaphors of digital transformation, by contrast, obscure the melting of industrial technological worlds in the digital age, typically by communicating industrialist images of digital technologies. Metaphors like "data is the new oil" (or the "new gold"), "data stream" (delivery of data), "data mining" (extraction of insights from data), "cloud" (place to store data) are inappropriate because they present data as a natural resource, pregiven and up for grabs (falsely 
hiding the brutal violence that comes with extractivism), which can be industrially exploited in the course of progress. Thereby they mask that "data" is not some autonomous entity, but instead, is highly dependent on human affairs. Misplaced metaphors hide that data is a social construct, generated through myths, social relations, often pre-existing networks of established stakeholders, and involve replication of media processes by such stakeholders (Couldry et al, 2014; Lupton, 2015, pp. 101-107; Noble, 2018, p. 100). By "naturalizing" and "depersonalizing" data, misplaced metaphors mask the stories, values, interests, prejudices, perspectives, behavior, relations, communications, etc. that make up all data (Tsoukas, 1997; Hwang and Levy, 2015). By presenting data as natural resources ready to be industrially exploited, economization (and, correspondingly, de-intellectualization) of data is normalized: data and data analytics have become the business of the tech oligarchs like Google and Facebook, with misinformation, mischaracterization, and stereotyping typically being profitable business (Dickel and Schrape, 2017; Fuchs, 2017b; Noble, 2018).

Misplaced metaphors not only fail to enhance enlightenment (cf. Pigliucci and Boudry, 2011) but actively contribute to distorting reality. This makes misplaced metaphors fraudulent. The fraudulent myth of digital transformation is sustained through misplaced metaphors that communicate fraudulent images of the digital age. Sheldon Ungar gives the example of the "knowledge society" as an example of a misplaced metaphor. Ungar stresses that through the digital transformation (economization) of the aesthetic and intellectual spheres, creativity, imagination and intellect are repressed. The promise of more knowledge in the digital age, accordingly, cannot be fulfilled since the intellectual sphere, from which knowledge emerges, is dominated. This explains why the increase in information - re-baptized as knowledge - goes hand in hand with a decline of literacy, illustrated by the rise of skimming (instead of reading), and "speedreading," abbreviations, the use of simple and simplifying texts, etc. As Ungar (2003, p. 332) puts it, "processes underlying the information revolution are serving to increase ignorance in society and potentially giving rise to a "knowledge-aversive culture'." The metaphor of the "knowledge society" hides the fact that an economized world is marked by the knowledge-averse culture of the digital age that today is associated with algorithmic phenomena like "data scandals", "post-truth", "alternative facts", "algorithms of oppression", and what Ed Finn $(2017$, p. 6) calls the "myth of the algorithm" and its "incantatory magic of words and codes" (Finn, 2017, p. 196). The so-called knowledge society is a technological world in which the imagination is repressed, and, therefore, the role of the intellect in human affairs and the corresponding quest for knowledge or enlightenment is highly limited. The socalled "knowledge economy", marked by digital transformation and the rise of tech firms, is an anti- 
intellectual world, in which knowledge is reduced to data; and data is economized, that is, reduced to commodity (cf. Tsoukas, 1997).

Other fraudulent metaphors that appear popular in the digital era include metaphors of the "digital community". "machine learning", and "the mind as computer". The metaphor of digital community is misplaced because, as Bauman's genuine metaphor of liquidity reveals, digital transformation is a process that un-fixes everything, including the face-to-face, bodily, intimate, interpersonal community bonds and shared traditions, which are the elements of a community. As Sharon Turkle (2015, pp. 3-4) points out, community existence is marked by face-to-face conversation, which is, as she emphasizes, the most human and humanizing thing people do. It is by being fully present to one another in conversational bonds that people learn to listen to others and develop the poetic sensibility and intellectual capacity for dialogical engagement, imagination, empathy, the acceptance of otherness, and self-reflection. It is through such conversational bonds that the intellectual sphere can flourish. Digital transformation is a process that replaces the face-to-face conversations of communities by digital connectivity and the constant feed of information and entertainment by tech oligarchies that is mistakenly imagined as a "living community". Digital transformation, Turkle (2015, p. 19; p. 21) stresses, facilitates "the flight from conversation", into "the efficiencies of mere connection." The metaphor of digital community is fraudulent because it hides the fact that digital connection breaks down community: digital connection implies efficient, economic communication (for instance, via texting), without the social constraints, duties, traditions and responsibilities of belonging to a community. In a similar way, machine learning and the mind as computer metaphors are misplaced (cf. Pigliucci and Boudry, 2011; Meloni, 2014; Carbonell, Sánchez-Esguivillas and Carro, 2016). It is a fraudulent metaphor because the mind, differently from data processing and its rule-governed (formal, mechanized, computational) language, develops through cultivation of the mind in the aesthetic and intellectual spheres. This cultivation of the mind, of the desire for learning and the art of conversation, matures through wondering, questioning, listening, imagining, revealing, empathizing, and self-reflecting. Hence, the misplaced metaphor of the mind as computer: computers and the so-called artificial "intelligence" technologies are mindless sets of mechanical procedures. Machine learning does not emerge from the intellectual sphere and does not manifest academic standards of thought, taste and feeling, but is driven by the desire to make the world calculable and efficient, that is, to further the mechanization (or "iron caging") of the world (cf. Berry, 2014; Fuchs, 2017b; Finn, 2017).

In sum, the misplaced metaphors of the digital age - metaphors that sustain the fraudulent myth of digital transformation - convey false images of the digital age in which the digital transformation 
amounts to a flourishing intellectual sphere. Such misplaced metaphors provide a false image of the digital age as a world of enlightenment, a knowledge economy or smart governance. Misplaced metaphors hide the economic domination of the intellectual sphere. The misplaced metaphors of the digital age obscure how an economized intellectual sphere generates a knowledge-averse culture, which social theory seeks to capture, criticize and negate. A particular renewed hermeneutic social theory can only do so if it is itself not an offspring of that knowledge-averse culture and its misplaced metaphors, but, instead, commits itself to keeping alive the struggle for a culture of enlightenment in the digital age (cf. Fuchs, 2017a).

\section{Concluding remarks}

In this article, it has been argued that old Weberian social theory needs to be renewed in order to fruitfully theorize the new realities of the digital era. Digital transformation is here understood as a Silicon Valleydriven process of algorithmic modernization, in which tech oligarchies like Google, Amazon and the top 25 Al companies manifest themselves as knowledge-averse forces (cf. Finn, 2017; Noble, 2018). Other types of renewed social theory may provide other definitions of economization and generate different sorts of social theoretic insights. In Luhmann's systems theory, for instance, autopoietic function systems like religion, polity and economy inter-relate with other systems such as health and sports, without being able to "dominate". Thus understood, economization is but an "observational bias" which comes with flawed social theory, namely, social theory that neglects the diversity of function systems (cf. Roth et al, 2017; Roth, 2015). From a Luhmannian perspective, the task of new social theory may well consist of defeating "the self-reinforcing and self-justifying diagnoses of the proliferating economisation of society" (Roth et al, 2018, p. 42). While Luhmann's systems theory is most useful for dimming "our passion for the economy and turn up our interest in some of the so far neglected function systems of society" (Roth, 2015 , p. 122), in this article hermeneutic social theory is renewed for generating awareness of how digital transformation tends to go hand in hand with the reinforcement of falsehood, fraudulence, prejudices, "post-truth", "alternative facts", etc. In the context of this paper, the particular meaning of economization is that of domination of the aesthetic and intellectual spheres by tech powers that shape the process of digital transformation, to the point that the poetic and sociological imagination may eventually become too weak to resist the anti-enlightenment found in the fraudulent myths and misplaced metaphors of the digital age. A renewed hermeneutic social theory, made fit for the digital age, must resist that tendency, for the very survival of hermeneutic social theory. 
In both the industrial and digital ages, the awkward anti-aesthetic and anti-intellectual reality of economic domination is hidden by fraudulent myths and misplaced metaphors that obscure rather than enlighten the mind. In the industrial age, social theorists like Horkheimer, Adorno, and Mills sought to uncover such fraud, in defense of the culture of mind - a culture to which also a renewed social theory belongs. Digital transformation and algorithmic modernization is mainly engineered by Silicon Valley forces. The digital domination of the aesthetic and intellectual spheres is found in the new fraudulent myths and misplaced metaphors that are rampant in the digital age. Such myths, signs of usurpation, hide a domination that generates oligarchic power structures, poverty of imagination, decline of poetic sensibility, conversation and empathy, shallow obsession with digital gadgets, in sum, knowledge aversion (cf. Collin and Pedersen, 2015; Duff, 2016; Aschoff, 2018). What follows from this line of argumentation is that the task of a renewed hermeneutic social theory is twofold: to criticize and negate the antiintellectual structures and corresponding knowledge-averse culture of the digital age; and to cultivate the poetic sensibility and and intellectual capacity to face an open universe and imagine one beyond usurpation of dominating value spheres.

It is a task for hermeneutic social theorists that begins with the care for the aesthetic sphere; that is, the care for a rich language, for genuine myths, and for appropriate metaphors. A particular renewed social theory therefore has to resist the Silicon Valley language and its corporate proxy languages, stories and images of the economic sphere. The criticism of digital transformation or the googlization of everything does not necessarily amount to a demonization of algorithmic technologies or of information capitalism. Whether digital technologies do ease the burdens of cultural (aesthetic and intellectual) existence and whether they do facilitate enlightenment depends on several factors. First, such technologies, algorithms in particular (cf. Finn, 2017), should be stripped of their enchanting magical aura and perceived as powerful tools that - just like their industrial counterparts - can annihilate whole worlds. This means that the myths that accompany them should be negated. Such poetic negation is in turn only possible if the economic sphere is again trimmed back to modest proportions. That would be a digital transformation subservient to aesthetic and intellectual ends, without the poetic and sociological imagination being sacrificed to economic purposes. This would imply the design of algorithmic technologies, including artificial intelligence, beyond mechanization. Second, and related to the previous precondition, the aesthetic and intellectual spheres should be allowed to develop according to their own principles, so that a rich poetic and sociological imagination may develop. And, finally, the application and proliferation of digital technologies have to be controlled, not by their owners and other stakeholders, of course, but by intellectual powers. As long as this is the case, an important task of the hermeneutic type 
of social theory will have to be negation and criticism, however difficult that might be in a digitally transformed yet knowledge-averse world that is dominated by overwhelming tech oligarchies.

\section{References}

Andriole, S.J., 2017. Five myths about digital transformation. MIT Sloan Management Review, 58(3), 2022.

Aschoff, N., 2018. The utopian impulse: from the Soviet Union to Silicon Valley. Socialism and Democracy, 32(1), 99-103.

Berry, D.M., 2014. Critical theory and the digital. Bloomsbury Academic.

Betz, D.J., Stevens, T., 2013. Analogical reasoning and cyber security. Security Dialogue 44(2), 147-164.

Boomen, M. van de, 2014. Transcoding the digital: how metaphors matter in new media. Institute of Network Cultures.

Carbonell, J, Sánchez-Esguevillas, A, Carro, B., 2016. The role of metaphors in the development of technologies. The case of the artificial intelligence. Futures 84, 145-163.

Christensen, L.T., Cornelissen, J., 2015. Organizational transparency as myth and metaphor. European Journal of Social Theory 18(2), 132-149.

Clegg, S.R., 2015. Reflections: why old social theory might still be useful. Journal of Change Management 15(1), 8-18.

Collin, F., Pedersen, B. D. 2015. The Frankfurt School, science and technology studies, and the humanities. Social Epistemology 29(1), 44-72.

Cohen, A., 2010. Myth and myth criticism following the Dialectic of Enlightenment. The European Legacy 15(5), 583-598.

Coleman, J.S., 1990. Foundations of social theory. Harvard University Press.

Couldry, N., 2014. Inaugural: A necessary disenchantment: myth, agency and injustice in a digital world. The Sociological Review 62(4), 881-897.

Dickel, S., J. Schrape, 2017. The logic of digital utopianism. Nanoethics 11, 47-58.

Dourish, P., Bell, G., 2011. Divining a digital future: mess and mythology in ubiquitous computing. The MIT Press.

Duff, A.S., 2016. Rating the revolution: Silicon Valley in normative perspective. Information, Communication \& Society 19(11), 1605-1621. 
Finn, E., 2017, What algorithms want: imagination in the age of computing. The MIT Press.

Fuchs, C., 2017a. Marx's Capital in the information age. Capital \& Class 41(1), 51-67.

Fuchs, C., 2017b. Günther Anders' undiscovered critical theory of technology in the age of big data capitalism. Triple C 15(2).

Hess, A., Davisson, A. (eds), 2018. Theorizing digital rhetoric. Routledge.

Jacobsen, M.H., Marshman, S., 2008. Bauman's metaphors: the poetic imagination in sociology. Current Sociology 56(5), 798-818.

Jordan, T., 2015. Information politics: liberation and exploitation in digital society. Pluto Press.

Hwang, T., Levy, K., 2015. "The cloud" and other dangerous metaphors. The Atlantic, 20 January 2015.

Laan, J.M. van der, 2004. Temptation and seduction in the technological milieu. Bulletin of Science, Technology \& Society 24(6), 509-514.

Lakoff, G., Johnson, M., 1980. Metaphors we live by. The University of Chicago Press.

Lash, S. 1990. Sociology of postmodernism. London: Routledge.

Lindgren, S., 2017. Digital media \& society. Sage.

Luhmann, N., 1982. The differentiation of society. Colombia University Press.

Lunt, N., 2005. A note on political science and the metaphorical imagination. Politics 25(2), 73-79.

Lupton, D., 2015. Digital sociology. Routledge.

Meloni, M., 2014. How biology became social, and what it means for social theory. The Sociological Review 62, 593-614.

Mills, C.W., 2000. The sociological imagination. Oxford University Press.

Mumford, A., 2015. Parallels, prescience and the past: analogical reasoning and contemporary international politics. International Politics 52(1), 1-19.

Nerlich, B., Clarke, D.D., 2001. Mind, meaning and metaphor: the philosophy and psychology of metaphor in 19th century Germany. History of the Human Sciences 14(2), 39-61.

Noble, S.U., 2018. Algorithms of oppression: how search engines reinforce racism. New York University Press.

Oakes, G., 2003. Max Weber on value rationality and value spheres. Journal of Classical Sociology 31(1), 27-45.

Ossewaarde, M., 2018. "Crises of modernity" discourses and the rise of financial technologies in a contested mechanized world. Philosophy \& Technology 31(1), 59-76.

Philip, K., Irani, L., Dourish, P., 2012. Postcolonial computing: a tactical survey. Science, Technology \& Human Values 37(1), 3-29. 
Pigliucci, M., Boudry, M., 2011. Why machine-information metaphors are bad for science and science education. Science \& Education 20, 453-471.

Roth, S., 2015. Free economy! On 3628800 alternatives of and to capitalism. Journal of Interdisciplinary Economics 27(2): 107-128.

Roth, S., 2017. Marginal economy: growth strategies for post-growth societies. Journal of Economic Issues, 51:4, 1033-1046.

Roth, S., Clark, C. Trofimov, N., Mkrtchyan, A., Heidingsfelder, M., Appignanesi, L., Perez Valls, M., Berkel, J., Kaivo-Oja, J., 2017. Futures of a distributed memory: a global brain wave measurement (1800-2000). Technological Forecasting and Social Change 118, 307-323.

Roth, S., Valentinovc, V., Augustinaitis, A., Mkrtichyan, A., Kaivo-oja, J., 2018. Was that capitalism? A future-oriented big data analysis of the English language area in the 19th and 20th century. Futures 98, 41-48.

Runciman, W.G., 2008. Forgetting the founders. The Sociological Review 56, 358-369.

Schmidt, J., 1998. Language, mythology, and enlightenment: historical notes on Horkheimer and Adorno's Dialectic of Enlightenment. Social Research 65(4), 807-838.

Schroeder, R. 2018. Social theory after the Internet: media, technology and globalization. UCL Press.

Schroeder, R., Swedberg, R., 2002. Weberian perspectives on science, technology and the economy. British Journal of Sociology 53(3), 383-401.

Schroeder, R., Ling, R., 2014. Durkheim and Weber on the social implications of new information and communication technologies. New Media \& Society 16(5), 789-805.

Swedberg, R., 2014. The art of social theory. Princeton University Press.

Tsoukas, H., 1997. The tyranny of light: the temptations and the paradoxes of the information society. Futures 29(9), 827-843.

Turkle, S., 2015. Reclaiming conversation: the power of talk in a digital age. Penguin.

Ungar, S., 2003. Misplaced metaphor: a critical analysis of the "knowledge society". Canadian Review of Sociology 40(3), 331-347.

Vaidhyanathan, S., 2012. The googlization of everything (and why we should worry). Berkeley: University of California Press.

Valentinov, V., Roth, S., Will, M.G., 2018. Stakeholder theory: a Luhmannian perspective. Administration and Society, 1-14.

Wajcman, J., 2017. Automation: is it really different this time? British Journal of Sociology 68(1), 191-127.

Weber, M., 1958. From Max Weber: essays in sociology. Oxford University Press. 
Williamson, B., 2017. Educating Silicon Valley: corporate education reform and the reproduction of the techno-economic revolution. Review of Education, Pedagogy, and Cultural Studies, 39(3), 265-288. 